\title{
Work related stressors and quality of life of nurses
}

\author{
Jelena Pavlović, Maja Račić, Nataša Radović, Sandra Joković, Natalija Hadživuković \\ University of Sarajevo, Faculty of Medicine, \\ Studentska 5, 73300 Foca, Republic of Srpska, Bosnia and Herzegovina \\ pjelena551@gmail.com; porodicnamedicina@gmail.com; natasall22@live.com; \\ sandra.jokovic@hotmail.com; natalijahadzivukovic@yahoo.com
}

\begin{abstract}
Introduction: Burnout syndrome is a state of mental and physical exhaustion caused by excessive and prolonged stress. The aim of the research was to determine the influence of stress factors on the quality of life of workers in the surgical and internal medicine department. Methodology: The study was designed as a cross-sectional study with 150 subjects. The research was conducted at the University Hospital Foca, surgical and internal medicine department. We used a sociodemographic questionnaire, a questionnaire to assess the health status and the work related scale of stress. Statistical analysis was performed using the SPSS ver. 24.o. Results: The frequency of the burnout syndrome as a response to chronic stress is high (20\%). The lower level of the quality of life of the respondents was found in dimension mental health (49.36\%) and vitality (62.93\%). Workers on the surgical ward are most obvious overloaded $(82.60 \%)$ and have a lower quality of life. Disscussion and Conclusion: The most common stress-related factors of workers in the surgical department are overloaded with work, financial constraints, call time, a small number of health care workers.

Keywords: professionals, stressful factors, nurses, quality of life
\end{abstract}

$\tau \mathrm{n}$

$n$ recent years, the greatest attention of the scientific public has been attracted by the number of studies of the influence of stress or stress factors on the health status of employees (Kang et al., 2015; Rybojad et al., 2016).Therefore, the rate of interest in the study of stress and its consequences on employees in the health sector increases (Lin et al., 2015; Kowalczuk and Krajewska-Kulak, 2015). Research of stress in the workplaces in the health sector with the aim of preventing its harmful effects, which lead to lower life quality and reduction of working capacity due to illness, becomes increasingly important (Romano et al, 2015). Neither the students in scientific disciplines are exempt from stress, 
especially those who are preparing for future positions in the medical profession (Kaewanuchit et al., 2015).In 1984 in the journal Nursing Mirror, Hingly wrote the following: "Nursing is by its very nature, a profession that is experiencing high levels of stress. Nurses are faced with suffering, pain and death; nursing interventions are not appreciative and spirited. Many are, by normal standards, unpleasant, others are degrading and some are scary" (Hingly, 1984, pp.19-22). Some researchers have questioned whether the cited sources of stress in the scientific literature, similar or the same for all nurses employed in hospitals or depend on the type of department. One of the areas of nursing that particularly attract attention of scholars are departments of emergency medicine and intensive care units, departments of surgery and oncology ward. There is agreement that the experience of stress caused by work diminishes the quality of nursing work (reducing the job satisfaction increased psychiatric morbidity and may contribute to the occurrence of some forms of physical diseases, particularly cardiovascular diseases and musculoskeletal system). Because of the importance and sensitivity of the work performed by nurses, interest in researching the quality of life and psychosocial aspects of their working environment emerged. Although quality of life and job satisfaction are different constructs, data from the literature show that they are mutually connected and that there are factors that affect both constructs (Stacciarini and Troccoli, 2004). The aim of the research was to determine the influence of stress factors on the quality of life between patients in the surgical and internal department.

\section{Methods}

The study was designed as a cross-sectional study with 150 respondents and was conducted University Hospital Foca surgical and internist wards, in the period from February 2016 to June 2016. Criteria for inclusion in the study were: respondents who work at least one year and are directly involved in the care and treatment of patients. Criteria for exclusion from the study were: respondents who work less than one year, patients who are not involved in the care and treatment of patients and subjects who did not respond to five or more questions or have circled the same answers to all the questions. The survey used sociodemographic questionnaire, a questionnaire to assess the health status (Short Form-36 Health Survey SF-36) (Ware, 1993) and the scale of stress in the workplace of hospital health workers ie. modified questionnaire based on the basis of a standardized questionnaire OSQ (Lindblom, 2006).The modification was made by selecting only a part of the question from the questionnaire, which was supplemented with specific issues related to the health profession. Respondents were offered 37 related to work stressors related to work organization, shift work, career advancement, education, professional requirements, interpersonal communication, communication of healthcare workers with patients, and fear of dangers (Lindblom, 2006).Statistical analysis was performed using SPSS ver. 24.0. The statistical test used was -squared test. As the level of statistical significance of differences, taken a common value of $\mathrm{p}<0.05$. For dis- 
playing the average values the arithmetic mean and standard deviation were used. The correlation is done with the help of the Pearson and Sperman correlation coefficient test.

\section{Results}

The study included 150 respondents, aged 20 years and over, and the average age was 39.97 years $(S D=12.84)$. The youngest patient was 20 years old while the oldest participant was 60 years old. The share of the female population in this, as well as in the majority of similar studies were dominant (72\%), which is expected, when it comes to the profession. There was a significant difference in terms of age and sex $\left(\chi^{2}=17,987 ; \mathrm{p}<0.001\right)$. More than half of respondents are (66\%) while the remaining $34 \%$ are not married.

\section{Table 1: Arithmetical means and standard deviations domain of the SF- 36 questionnaire with nurses and technicians working in surgical and internal medicine department.}

\begin{tabular}{|c|c|c|c|}
\hline \multirow[b]{2}{*}{ Domains of the SF-36 questionnaire } & \multicolumn{3}{|c|}{$\begin{array}{c}\text { Workplace of respondents } \\
\text { Mean (SD) }\end{array}$} \\
\hline & Surgery department & $\begin{array}{l}\text { Internal medicine } \\
\text { department }\end{array}$ & $\begin{array}{l}\text { Surgery and inter- } \\
\text { nal medicine de- } \\
\quad \text { partment }\end{array}$ \\
\hline Physical functioning & $83.80(16.78)$ & $86.32(18.39)$ & $85.20(17.68)$ \\
\hline Limitation due to physical health & $73.13(36.49)$ & $76.50(37.92)$ & $75.00(37.20)$ \\
\hline Body pain & $79.55(24.06)$ & $82.40(24.43)$ & $81.13(24.22)$ \\
\hline General health & $69.17(14.83)$ & $72.71(18.63)$ & $71.13(17.07)$ \\
\hline Vitality & $60.59(13.58)$ & $64.81(13.97)$ & $62.93(13.91)$ \\
\hline Social functioning & $70.29(24.20)$ & $74.36(26.03)$ & $72.55(25.23)$ \\
\hline Limitation due to emotional problems & $71.08(16.78)$ & $86.32(18.39)$ & $73.93(36.26)$ \\
\hline Mental health & $49.94(6.66)$ & $48.90(7.05)$ & $49.36(6.88)$ \\
\hline Body health component & $76.37(17.73)$ & $79.39(19.65)$ & $78.04(18.81)$ \\
\hline Mental component of health & $63.43(15.37)$ & $66.56(14.69)$ & $65.16(15.03)$ \\
\hline
\end{tabular}

Between the the groups of different places of work no statistically significant difference in physical function as a measures of physical health, with the largest percentage of respondents (84\%) belong to the category of excellent physical function, $14 \%$ belong to a group that has a good physical functioning, while only $2 \%$ of respondents have a poor physical functioning. Very good functioning $64 \%$ of respondents, $26 \%$ have a good level of functioning, while $10 \%$ of respondents have a poor level of social functioning. Expressed limitations due to emotional problems has $27.3 \%$ of respondents, moderate limitations 
has $2.7 \%$ of respondents, while the majority of respondents (70\%) do not have due to emotional problems. That respondents who work at the surgical department rated stress factors at work with the highest grades in higher percentage compared to respondents who work at the internal department: work overload $(82,60 \%)$,financial constraints $(79,70 \%), 24$-hour responsibility $(73,60 \%)$, oncall duty $(68,53 \%)$, unforeseen situations $(50,53 \%)$, incurable patients $(51,46 \%)$, a small number of health workers $(48,40 \%)$, public criticism $(63,43 \%)$.Pearson's correlation coefficient ( $\mathrm{r}$ ) has shown that there is a statistically significant correlation between workplace stress and quality of life of respondents working at the surgical and internal department $(\mathrm{r}=0,263 ; \mathrm{p}<0,001)$. That correlation is low and negative for respondents who fall under the category of those who are more exposed to stress in the workplace show a poorer physical and mental component of life quality (Table 2).

Table 2: Correlation coefficients between total stress-related to work and quality of life of the respondents.

\begin{tabular}{|c|c|c|c|}
\hline $\begin{array}{l}\text { Stress in the workplace } \\
\text { and the quality of life }\end{array}$ & The correlation coefficient & $\begin{array}{c}\text { Stress in the workplace } \\
\text { and the quality of life } \\
\text { (total score) }\end{array}$ & The quality of life \\
\hline \multirow{3}{*}{$\begin{array}{l}\text { Stress in the workplace } \\
\text { (total score) }\end{array}$} & $\begin{array}{l}\text { The correlation coeffi- } \\
\text { cient }(r)\end{array}$ & 1 & -0.263 \\
\hline & $\mathrm{p}$ & & 0.001 \\
\hline & Number of respondents & 150 & 150 \\
\hline \multirow{3}{*}{ The quality of life } & $\begin{array}{l}\text { The correlation coeffi- } \\
\text { cient }(r)\end{array}$ & -0.263 & 1 \\
\hline & $\mathrm{p}$ & 0.001 & \\
\hline & Number of respondents & 150 & 150 \\
\hline
\end{tabular}

\section{Discussion}

Our research has shown that healthcare workers show the best quality of health in physical functioning, absence of physical pain, limitations due to physical health problems and limitations due to emotional problems, in social functioning and general health. A lower level of health quality is seen in the median values of mental health and vitality. The most frequent factors of stress in our research: work overload, financial constraints, $24 \mathrm{~h}$ responsibility, duty, contingency, incurable patients. Respondents who are more exposed to stress 
in the workplace showed poorer physical and mental component of quality of life According to our research, the level of stress among nurses is very high (6o\%). The difference was also observed in the view that financial constraints are one of the main stressors. Quality of life is obviously the first psychological category, which does not arise automatically from satisfying certain basic needs, but from the whole psychological structure of the individual interacting with the physical and social environment in which he lives. The results of our research have shown that nurses rated their physical health as excellent, while mental health was rated as good. Compared to similar studies, the results of our research were significantly better than the results of the study conducted in Chile (Andrades Barrientos and Valenzuela Suazo, 2007), and lower than the results of the study carried out in Turkey (Cimete, 2003). By analyzing the quality of life domains, it has been found that nurses have shown the best quality of health in physical functioning, absence of physical pain, limitations due to problems in physical health, limitations due to emotional problems, social functioning and general health. Positive emotions at work are associated with better health, a higher degree of job satisfaction, responsible behavior at work, higher work performance and quality of work, greater resistance to stress and burnout, less likely to change jobs, better relations with other people (Habazin, 2013).

\section{Conclusions}

The workplace significantly influences the emergence of stress. Respondents working at the surgical department have a higher level of stress compared to respondents working at the internal department, and there is a significant correlation between professional stress and quality of life. Respondents who are more exposed to professional stress show a lower level of physical and mental components of life quality. The most frequent professional stress factors in the respondents are work overload, financial constraints, 24 hours of responsibility, on-call duty, unpredictable situations, incurable patients, a small number of health workers and public criticism.

\section{References}

ANDRADES BARRIENTOS, L. and VALENZUELA SUAZO, S., 2007. Quality of life associated factors in Chileans hospitals nurses. Revista Latino-Americana de Enfermagem, vol. 15, no. 3, pp. 480-486.

CIMETE, G., GENCALP, N.S. and KESKIN, G., 2003. Quality of life and job satisfaction of nurses. Journal of Nursing Care Quality, vol. 18, no. pp.151-158.

HABAZIN, I., 2013. The association with emotional behavioral and physiological response to the work of nurses and technicians in hospitals. Croatian Review of Rehabilitation Research, vol. 49, no.1, pp. 37-48. 
HINGLY, P., 1984. The humane face of nursing. Nursing Mirror, vol. 159, no. 21, pp. 19-22.

KAEWANUCHIT C., MUNTANER C. and ISHA, N., 2015. A Causal relationship of occupational stress among university employees. Iranian Journal of Public Health, vol. 44, no. 7, pp. 931-938.

KANG, S.H., BOO, Y.J., LEE, J.S., HAN, H.J., JUNG, C.W. and KIM, C.S., 2015. High occupational stress and low career satisfaction of Korean surgeons. Journal of Korean Medical Science, vol. 30, no. 2, pp. 133-139.

KOWALCZUK, K. and KRAJEWSKA-KULAK, E., 2015. Influence of selected sociodemographic factors on psychosocial workload of nurses and association of this burden with absenteeism at work. Medycyna pracy, vol. 66, no. 5, pp. 615-624.

LIN, C., WANG, L. and ZHAO, Q., 2015. Factors related to health-related quality of life among Chinese psychiatrists: occupational stress and psychological capital. BMC health services research, vol. 22, no. 15, pp. 20-27.

RYBOJAD,B., AFTYKA, A., BARAN, M. and RZONCA, P., 2016. Risk factors for posttraumatic stress disorder in Polish paramedics: a pilot study. Journal ofEmergencyMedicine, vol.50, no.2, pp. 270-276.

ROMANO, M., FESTINI F. and BRONNER, L., 2015. Cross-sectional study on the determinants of work stress for nurses and intention of leaving the profession. Professioni Infermieristiche, vol. 68, no.4, pp. 203-210.

STACCIARINI, J.M.R. and TROCCOLI B.T., 2004. Occupational stress and constructive thinking: health and job satisfaction. Journal of Advanced Nursing,vol. 46, no. 5, pp. 480-487. 